\title{
PAPER
}

\section{Effectiveness of bed rest after mild traumatic brain injury: a randomised trial of no versus six days of bed rest}

\author{
J R de Kruijk, P Leffers, S Meerhoff, J Rutten, A Twijnstra
}

J Neurol Neurosurg Psychiatry 2002;73:167-172

Background: Outcome after mild traumatic brain injury (MTBI) is determined largely by the appearance of post-traumatic complaints (PTC). The prevalence of PTC after six months is estimated to be between 20 and $80 \%$. Bed rest has been advocated to prevent PTC but its effectiveness has never been established.

Objective: To evaluate the effect of bed rest on the severity of PTC after MTBI.

Methods: Patients presenting with MTBI to the emergency room were randomly assigned to two intervention strategies. One group was advised not to take bed rest (NO) and the other to take full bed rest (FULL) for six days after the trauma. The primary outcome measures were severity of PTC on a visual analogue scale and physical and mental health on the medical outcomes study 36 item short form health survey (SF-36) at two weeks and three and six months after the trauma.

Correspondence to:

Dr J R de Kruijk,

Department of Neurology,

University Hospital

Maastricht, P Debeylaan

$25, \mathrm{NL} 6229 \mathrm{HX}$

Maastricht, The

Netherlands;

jdk@sneu.azm.nl

Received

17 October 2001

In revised form 4 April

2002

Accepted 22 April 2002
Results: Between October 1996 and July 1999, 107 (54 NO, 53 FULL) patients were enrolled. Outcome variables in both groups clearly improved between two weeks and six months. After adjustment for differences in baseline variables, most PTC tended to be somewhat more severe in the FULL group six months after the trauma, but no significant differences were found. Neither were there any significant differences in the outcome parameters between the two groups after three months. Two weeks after the trauma, most PTC in the FULL group were slightly less severe than those in the NO group, and physical subscores of the SF-36 in the FULL group were slightly better. These differences were not significant. Patients in the FULL group reported significantly less dizziness during the intervention period. Conclusions: As a means of speeding up recovery of patients with PTC after MTBI, bed rest is no more effective than no bed rest at all. Bed rest probably has some palliative effect within the first two weeks after the trauma.
M ild traumatic brain injury (MTBI) accounts for about $90 \%$ of all traumatic brain injuries..$^{1-3}$ In addition to the individual impairments, the burden to society is large in terms of hospital costs and loss of productivity resulting from post-traumatic complaints (PTC). ${ }^{45}$

Apart from very rare acute intracranial complications, outcome after MTBI is determined mostly by the appearance of PTC. Although the severity of most PTC declines during the first three months,${ }^{67}$ the prevalence of PTC after six months is estimated to be $20-80 \%{ }^{8-11}$ The huge variation in these estimates probably reflects mainly the different definitions of MTBI and PTC used in the various studies. In addition to PTC, both brain and non-brain (for example, musculoskeletal) injuries in patients with MTBI negatively affect general health status during the first year after the trauma. ${ }^{12}$

Education, rehabilitation, and drugs have been used with at best limited success in the prevention and treatment of PTC. ${ }^{513-19}$ The effectiveness of bed rest in preventing PTC has hardly been studied, with only one study seeming to suggest that longer bed rest leads to an increase in PTC. ${ }^{20}$ Notwithstanding this uncertainty about the efficacy of bed rest, many European neurologists (40\%) continue to recommend one or more days of full bed rest after MTBI. ${ }^{21}$

In general, doubt has been cast on the effectiveness of bed rest in many situations where it has traditionally been recommended. A recent review of randomised trials on bed rest for 15 other medical conditions concluded that bed rest did not improve the prognosis (for example, in uncomplicated myocardial infarction) or even that it worsened the outcome in some situations (for example, in spontaneous labour). ${ }^{22}$ We conducted a randomised trial of the effectiveness of six days of bed rest versus no bed rest in terms of the severity of PTC and general health status after six months.

\section{METHODS}

\section{Participants}

The study was approved by the institutional ethics committee of the Maastricht University Hospital and all patients provided written informed consent.

Patients were eligible for this study if they were older than 15 years and presented to the emergency department within six hours after the trauma. Duration of post-traumatic amnesia and presence of transient loss of consciousness were estimated on the basis of information from the patient or witnesses. MTBI was defined as a blunt blow to the head resulting in post-traumatic amnesia of less than one hour; initial loss of consciousness of less than 15 minutes; a Glasgow coma score of 14 or 15 on presentation to the emergency department; and absence of focal neurological signs. Patients were excluded if they suffered from multiple trauma or when clinical observation was necessary. Patients with a history of traumatic brain injury, alcohol abuse, or a psychiatric disorder were also excluded.

\section{Intervention}

The difference between the strategies compared was the amount of recommended bed rest between 800 am and 800 pm during the first 10 days after the trauma. Patients in the no bed rest group (NO) were instructed to be mobile from the first day after the trauma, with at most four hours of bed rest

Abbreviations: FULL, patients advised to take full bed rest; MTBI, mild traumatic brain injury; NO, patients advised not to take bed rest; PTC, post-traumatic complaints; SF-36, medical outcomes study 36 item short form health survey; VAS, visual analogue scale 


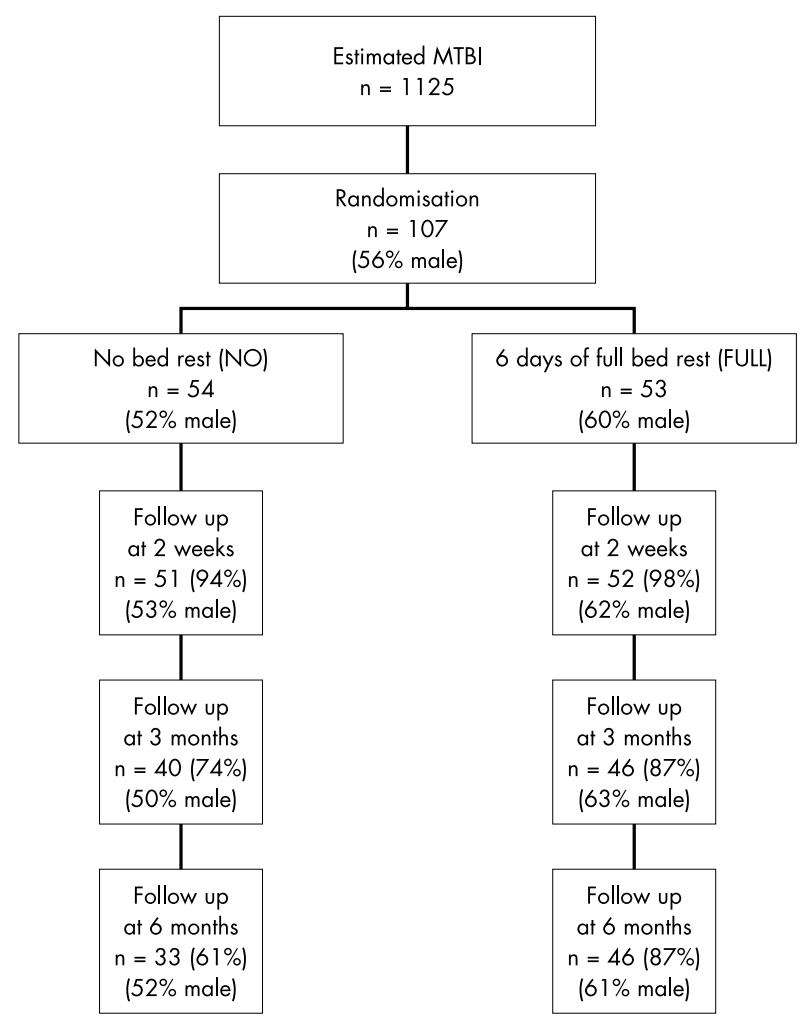

Figure 1 Trial protocol for patients with mild traumatic brain injury (MTBI) randomly assigned to no bed rest (NO) or to full bed rest (FULL) between October 1996 and June 1999.

on the first day, three hours on the second day, two hours on the third day, and one hour on the fourth day. Patients were expected to resume normal daily activities and work on the fifth day. Patients in the full bed rest group (FULL) were instructed to take full bed rest during the first six days following the trauma. Starting from day 7, patients were advised to follow the same mobilisation schedule given to the NO group. In summary, the comparison was between four days of decreasing amounts of rest, with return to full activity between days 1 and 5, and six days of full bed rest followed by return to full activity between days 7 and 11 . The maximum duration of bed rest in the NO group was to be 10 hours, divided over a maximum of four days, while the patients in the FULL group were expected to rest for a maximum of 82 hours over a maximum of 10 days (and 72 hours of bed rest over the first six days).

\section{Outcome variables}

The primary outcome variables were the severity of 16 PTC and general health status at two weeks, three months, and six months after the trauma. The PTC were divided into four subgroups (cognitive, dysthymic, vegetative, and physical) in accordance with an earlier study ${ }^{10}$ and were measured on a visual analogue scale (VAS). Using a VAS score with a range of 0-100 mm meant that the severity of the complaints was measurable in detail, rather than merely being recorded in terms of the presence or absence of the complaints. General health status was measured by means of the medical outcomes study 36 item short form health survey (SF-36; Dutch language version ${ }^{23}$ ), which is recognised as a standard general measure of physical and mental components of health status. $^{24}$

\section{Study design}

If patients fulfilled all admission criteria, written and oral explanations about the trial were given by the attending phy-
Table 1 Characteristics of patients after mild traumatic brain injury with (FULL) and without (NO) ful bed rest

\begin{tabular}{|c|c|c|}
\hline & NO $(n=51)$ & FULL $(n=52)$ \\
\hline Male sex (\%) & 52 & 60 \\
\hline \multicolumn{3}{|l|}{ Age (years) } \\
\hline Mean (SD) & $39.9(14.5)$ & $34.1(16.5)$ \\
\hline Range & $15-72$ & $17-76$ \\
\hline \multicolumn{3}{|l|}{ Education (\%) } \\
\hline Low level & 30 & 32 \\
\hline Special & 7 & 4 \\
\hline Medium level & 31 & 42 \\
\hline Higher/university level & 24 & 19 \\
\hline Unknown & 7 & 4 \\
\hline \multicolumn{3}{|l|}{ Social situation (\%) } \\
\hline Living alone & 52 & 36 \\
\hline Married & 35 & 51 \\
\hline Living with other person(s) & 6 & 8 \\
\hline Other & 7 & 3 \\
\hline \multicolumn{3}{|l|}{ Cause of accident (\%) } \\
\hline Traffic & 43 & 53 \\
\hline Work & 17 & 19 \\
\hline In or around the house & 13 & 9 \\
\hline Sports & 13 & 6 \\
\hline Violence & 9 & 8 \\
\hline Unknown/other & 6 & 6 \\
\hline \multicolumn{3}{|c|}{ Reported symptoms in the emergency room (\%) } \\
\hline Loss of consciousness & 80 & 77 \\
\hline Mean (SD) PTA (minutes) & $19(17)$ & $19(19)$ \\
\hline Headache & 54 & 70 \\
\hline Dizziness & 13 & 21 \\
\hline Nausea & 30 & 25 \\
\hline Vomiting & 11 & 2 \\
\hline
\end{tabular}

sician (a neurology resident). A consent form was signed by the patient and the physician before the patient was enrolled. To obtain equal group sizes, randomisation was done in blocks of two and four. The sequence of block sizes was determined at random.

The sex and age of the patient, the cause of the accident, and the presence of headache, nausea, vomiting, and dizziness were recorded at the first examination. Traumatic injuries to limbs, trunk, or head were also recorded and, if necessary, a radiological examination was performed. The assigned advice was explained by the physician and it was also clearly summarised on the first page of the medical diary that each patient received. To evaluate their compliance, patients were asked to note the daily number of hours of bed rest during the first 10 days following the trauma. This diary also contained questions about the use of analgesics and recorded the severity of headache, dizziness, and nausea by means of a VAS. Another VAS was used to let patients score the level of difficulty they experienced in complying with the advice during a particular day. At the patient's discharge from the emergency department, the routine home observation instructions (to detect possible intracranial complications in the first 24 hours following the injury) were given to an accompanying person. At the follow up visits to the outpatient clinic, patients filled in questionnaires assessing the outcome variables.

\section{Analysis}

Baseline data including age and sex, and causes and symptoms of injury were compared between the NO and FULL groups. The total duration of bed rest (hours) during the first 10 days, the sum of the levels of difficulty (measured with a VAS score) experienced in complying with the assigned advice over the first four days, and the number of analgesic tablets used over the first four days were calculated and compared between the two groups. The same was done for headache, dizziness, and nausea during the first four days of intervention. Raw scores on the SF-36 were transformed to scaled 
Table 2 Characteristics of the two groups during the intervention

\begin{tabular}{|c|c|c|c|}
\hline & NO $(n=46)$ & FULL $(n=48)$ & $\begin{array}{l}\text { p Value } \\
\text { (Mann-Whitney U test) }\end{array}$ \\
\hline \multicolumn{4}{|c|}{ Hours of bed rest } \\
\hline $\begin{array}{l}\text { Mean (range) during days } 1-10 \\
\text { Excluding two patients with extreme bed rest duration ( } 260 \text { and } 158 \text { hours) }\end{array}$ & $\begin{array}{l}26(0-261) \\
17(0-72)\end{array}$ & $57(14-102)$ & \\
\hline $\begin{array}{l}\text { Difficulty complying with advice* } \\
\text { Median (5 and } 95 \text { percentiles) }\end{array}$ & $\begin{array}{l}71.0 \\
(0-391)\end{array}$ & $\begin{array}{l}118 \\
(0-363)\end{array}$ & 0.47 \\
\hline
\end{tabular}

scores ranging from 0 to 100, with higher scores reflecting better health or a lesser impact on functioning. The median VAS scores of the 16 PTC and the mean SF-36 scores for the various follow up occasions were compared between the NO and FULL groups. Since some of the baseline parameters differed between the two groups, differences in outcome between the two intervention groups were tested by means of multiple linear regression analysis of ln VAS scores of PTC and SF-36 scores on sex, social situation, and the presence of headache, dizziness, and vomiting in the emergency room.

\section{RESULTS}

Between October 1996 and June 1999, approximately 1125 patients with MTBI were seen at the University Hospital of Maastricht. ${ }^{3}$ One hundred and seven of these patients were enrolled in the study. The rest met the exclusion criteria, refused to be included, or were not asked by the attending specialist to participate. Ultimately, 54 patients received the NO bed rest advice and 53 received the FULL bed rest advice. Figure 1 shows the flow of the patients in the trial. Four patients were lost to follow up and nine patients did not fill in their medical diaries during the intervention. After two weeks, $95 \%$ of patients from the NO group and $98 \%$ of those from the FULL group were examined and interviewed. After three months and six months, more patients in the FULL group showed up for follow up ( $87 \%$ on both occasions) than in the NO group ( $74 \%$ and $61 \%$, respectively). The intervention groups were similar with regard to the distributions of age, educational level, cause of the accident, loss of consciousness, and duration of post-traumatic amnesia (table 1). The FULL group had relatively more male patients than the NO group $(60 \% \vee 52 \%)$ and fewer patients living alone (36\% v 50\%). Patients in the FULL group reported more headache and dizziness in the emergency room before they were randomly assigned to a group, whereas patients in the NO group vomited more.

\section{Intervention}

The mean duration of bed rest in the NO group was 26 hours. After the exclusion of two women who reported 260 and 158 hours of bed rest, the mean for this group became 17 hours (table 2). Patients in the FULL group rested for an average of 57 hours during the first 10 days after the trauma. Patients in the FULL group found it more difficult to comply with the advice during the first four days of intervention than those in the NO group (table 2), but this difference was not significant $(\mathrm{p}=0.47$, Mann-Whitney $U$ test $)$. Patients in the FULL group used more oral analgesics (median 3 ) than those in the NO group (median 1). This difference was not significant $(\mathrm{p}=0.47$, Mann Whitney U test $)$.

During the first four days of the intervention, patients in the FULL group suffered significantly less dizziness than those in the NO group (fig 2). Headache and nausea were also reported to be slightly (not significantly) less severe in the FULL group after adjustment for differences in baseline variables.

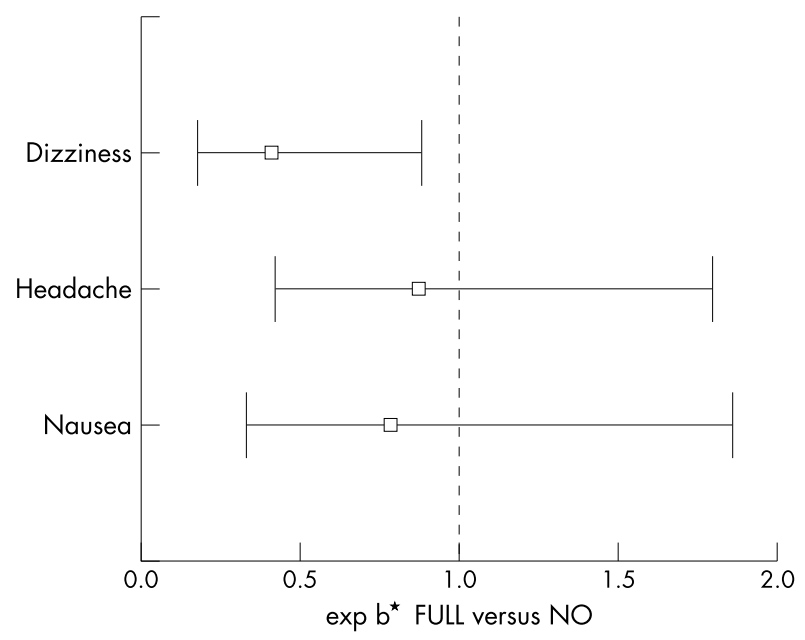

Figure 2 Symptoms during intervention in patients with (FULL) and without (NO) full bed rest. ${ }^{\star} b$, coefficients from linear regression analysis of In outcome variable (symptoms during intervention) on intervention (FULL versus NO) after adjustment for sex, social situation, headache, and dizziness and vomiting in the emergency room, measured in millimetres on visual analogue scale (VAS) scores for days 1-4. Bars indicate the $95 \%$ confidence intervals for $\exp \mathrm{b}$.

\section{Follow up}

In both intervention groups, severity of PTC diminished and SF-36 scores improved between two weeks and six months after the trauma (table $3^{3}$, table 4 ). After six months, patients in the FULL group reported slightly higher VAS scores on 12 of the 16 PTC after adjustment for baseline differences (fig 3). Only headache, flushing easily, being easily overwhelmed by problems, and having trouble concentrating scored somewhat lower. Apart from flushing easily, none of the differences were significant. Given that the medians for flushing easily were zero in both groups, the difference, though significant, was small. After six months, no significant differences in SF-36 scores were found between the two groups, though patients in the FULL group had slightly poorer scores on the bodily pain subscale of the SF-36 after adjustment for baseline differences (fig 4).

After three months, most PTC in the physical category were given slightly higher scores in the FULL group, whereas cognitive and dysthymic complaints tended to be given slightly lower scores in this group (fig 3 ). Patients in the FULL group had slightly better scores on almost all SF-36 subscales (fig 4). Only the difference for physical role functioning was more pronounced. None of these differences were significantly different after three months.

After two weeks, patients in the FULL group had slightly lower VAS scores than those in the NO group on 14 of the 16 PTC (fig 3). The only significant difference, however, was in feeling faint but since the medians for both groups were zero, the group difference was very small. Forgetfulness and crying more easily were given higher scores in the FULL group after two weeks. At this same follow up occasion, patients in the FULL group had higher scores on the SF-36 subscales of 
Table 3 Post-traumatic complaints (PTC) during follow up measured on a visual analogue scale

\begin{tabular}{|c|c|c|c|c|c|c|}
\hline \multirow[b]{2}{*}{ PTC category } & \multicolumn{2}{|l|}{ Two weeks } & \multicolumn{2}{|c|}{ Three months } & \multicolumn{2}{|c|}{ Six months } \\
\hline & $\begin{array}{l}\text { NO } \\
(n=51)\end{array}$ & $\begin{array}{l}\text { FULL } \\
(n=52)\end{array}$ & $\begin{array}{l}\text { NO } \\
(n=40)\end{array}$ & $\begin{array}{l}\text { FULL } \\
(n=46)\end{array}$ & $\begin{array}{l}\text { NO } \\
(n=33)\end{array}$ & $\begin{array}{l}\text { FULL } \\
(n=46)\end{array}$ \\
\hline \multicolumn{7}{|l|}{ Cognitive PTC } \\
\hline Trouble concentrating & $6(0-96)$ & $7(0-89)$ & $2(0-84)$ & $2(0-63)$ & $1(0-55)$ & $1(0-85)$ \\
\hline Easily overwhelmed by problems & $0(0-50)$ & $0(0-10)$ & $0(0-81)$ & $1(0-31)$ & $0(0-46)$ & $1(0-67)$ \\
\hline Forgetful & $7(0-61)$ & $13(21)$ & $4(0-82)$ & $5(0-62)$ & $1(0-30)$ & $4(0-83)$ \\
\hline \multicolumn{7}{|l|}{ Vegetative PTC } \\
\hline Flushing easily & $0(0-21)$ & $0(0-31)$ & $0(0-32)$ & $1(0-40)$ & $0(0-22)$ & $0(0-15)$ \\
\hline Feeling short of breath & $0(0-65)$ & $0(0-50)$ & $0(0-85)$ & $1(0-80)$ & $0(0-37)$ & $1(0-58)$ \\
\hline Feeling faint & 0 (0-77) & 0 (0-29) & $0(0-48)$ & $0(0-40)$ & $0(0-18)$ & $1(0-61)$ \\
\hline \multicolumn{7}{|l|}{ Dysthymic PTC } \\
\hline Depressed & $1(0-61)$ & $0(0-49)$ & $1(0-88)$ & $2(0-54)$ & $0(0-35)$ & $1(0-62)$ \\
\hline Drowsy & $23(0-91)$ & $8(0-95)$ & $3(0-85)$ & $2(0-75)$ & $2(0-72)$ & $3(0-91)$ \\
\hline Crying more easily & $0(0-55)$ & $0(0-49)$ & $0(0-88)$ & $1(0-41)$ & $0(0-17)$ & $1(0-42)$ \\
\hline Confused & $1(0-54)$ & $0(0-72)$ & $0(0-79)$ & $1(0-60)$ & 0 (0-29) & $1(0-71)$ \\
\hline \multicolumn{7}{|l|}{ Physical PTC } \\
\hline Headache & $17(0-100)$ & $9(0-94)$ & $0(0-50)$ & 4 (0-69) & $4(0-29)$ & $3(0-83)$ \\
\hline Dizziness & $15(0-90)$ & $11(0-96)$ & $0(0-58)$ & $3(0-77)$ & $1(0-42)$ & $4(0-72)$ \\
\hline Nausea & $0(0-68)$ & $0(0-43)$ & $0(0-26)$ & $1(0-76)$ & $0(0-19)$ & $0(0-57)$ \\
\hline Light headedness & $3(0-61)$ & $3(0-57)$ & $0(0-48)$ & $2(0-49)$ & $1(0-19)$ & $1(0-67)$ \\
\hline Paraesthesia of $\operatorname{arm}(\mathrm{s})$ & $0(0-67)$ & $0(0-36)$ & $0(0-46)$ & $1(0-73)$ & $0(0-24)$ & $1(0-68)$ \\
\hline Sleeping problems & $1(0-88)$ & $0(0-80)$ & $0(0-76)$ & 1 (0-94) & $0(0-57)$ & $1(0-70)$ \\
\hline
\end{tabular}

Table 4 Physical and mental health during follow up assessed using the medical outcomes study 36 item short form health survey (SF-36)

\begin{tabular}{|c|c|c|c|c|c|c|}
\hline \multirow[b]{2}{*}{ SF-36 category } & \multicolumn{2}{|l|}{ Two weeks } & \multicolumn{2}{|c|}{ Three months } & \multicolumn{2}{|l|}{ Six months } \\
\hline & NO $(n=51)$ & FULL $(n=52)$ & $\mathrm{NO}(n=40)$ & FULL $(n=46)$ & $\mathrm{NO}(n=33)$ & FULL $(n=46)$ \\
\hline $\begin{array}{l}\text { Physical functioning } \\
\text { Role functioning }\end{array}$ & $76(22)$ & $76(21)$ & $87(17)$ & $90(14)$ & $91(12)$ & $88(15)$ \\
\hline Physical & 41 (44) & $54(45)$ & $60(43)$ & $75(40)$ & 81 (35) & 77 (38) \\
\hline Emotional & $74(41)$ & $68(42)$ & $72(38)$ & $71(39)$ & $83(32)$ & $80(37)$ \\
\hline Social functioning & $65(30)$ & 63 (31) & $83(21)$ & 84 (19) & $86(19)$ & $86(21)$ \\
\hline Bodily pain & $53(23)$ & $44(23)$ & $74(23)$ & $78(25)$ & $84(19)$ & $74(27)$ \\
\hline Mental health & 74 (19) & 71 (17) & 75 (18) & 76 (18) & 76 (17) & 75 (19) \\
\hline Vitality & $57(23)$ & $60(23)$ & $65(20)$ & $65(22)$ & $66(18)$ & $68(24)$ \\
\hline General health perception & $75(21)$ & $72(16)$ & $71(21)$ & $72(16)$ & 74 (19) & $70(20)$ \\
\hline
\end{tabular}

Raw scores on the SF-36 were transformed to scaled scores ranging from 0 to 100 , where higher scores reflect better health or less impact on functioning Data are mean (SD).

physical role $(p=0.09)$ and vitality, both measuring physical health (fig 4). However, these patients scored slightly lower on emotional role functioning and had more bodily pain than those in the NO group. Again, none of the differences reached significance.

\section{DISCUSSION}

\section{Principal findings}

The results of the present study indicate that the advice to take six days of complete bed rest had no beneficial effect on the severity of PTC or on general health status at six months after MTBI.

\section{Relation to other studies}

Previous studies have addressed both the effectiveness of PTC prevention and the treatment of persistent PTC in patients with MTBI. However, a generally accepted treatment for patients with MTBI to prevent PTC has never been established. Educating patients about possible complications shortly after MTBI may help to reduce the severity of PTC later on. ${ }^{5131516}$ Pharmacological treatment seems to have little or no effect on either prevention or treatment of PTC..$^{17-19} 25$ The effectiveness of bed rest in patients with MTBI has never before been investigated in a randomised trial, though one study suggested that bed rest lasting more than two weeks after MTBI resulted in poorer outcome than briefer bed rest. ${ }^{20}$ Because this was an observational study, no conclusion about causality could be drawn. Indeed, the same association would have been found if a more severe trauma had led to both longer bed rest and more PTC.

In a recent survey in Europe, we found that many neurologists $(40 \%)$ recommend full bed rest after MTBI. The recommended period of bed rest ranged from 1-14 days. ${ }^{21}$ The study concluded that there was no consensus about recommendations for the length of bed rest, the length of work pause, and the need for any follow up of these patients.

\section{Strengths and weaknesses of the present study}

Estimated prevalence and severity of PTC in previous studies have often differed because different definitions of MTBI were used. The MTBI patient population in the present study was clearly defined according to the most recent opinion in the literature. ${ }^{7627}$

To evaluate compliance with the prescribed bed rest, we measured the actual duration of bed rest in both groups. Although patients in the NO group rested for too long (a mean of seven hours too long) and patients in the FULL group rested for less than the recommended number of hours (a mean of 15 hours less), a robust contrast between the intervention groups was obtained. 
PTC after two weeks

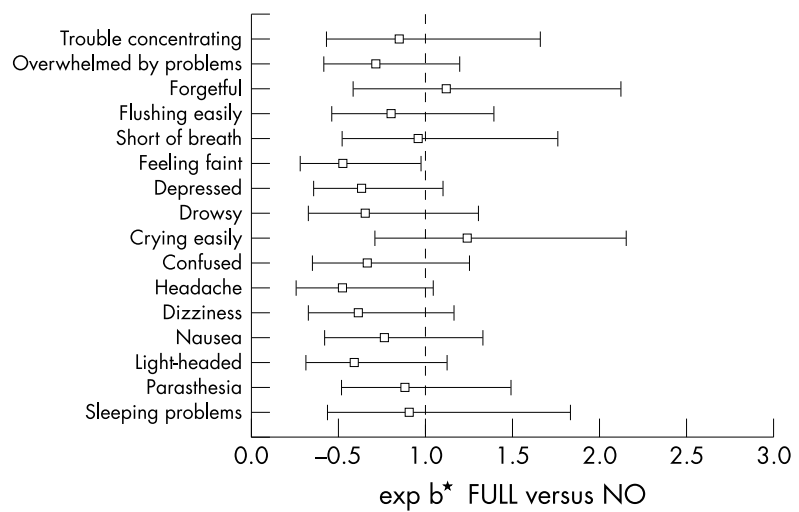

PTC after three months

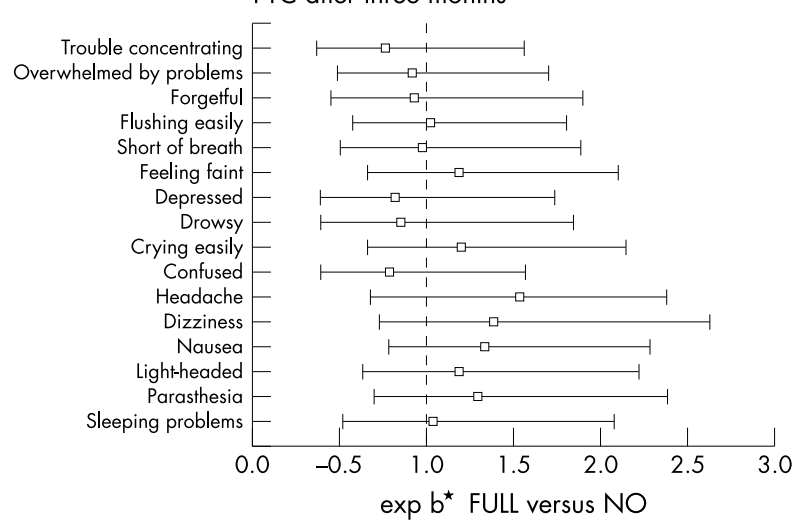

PTC after six months

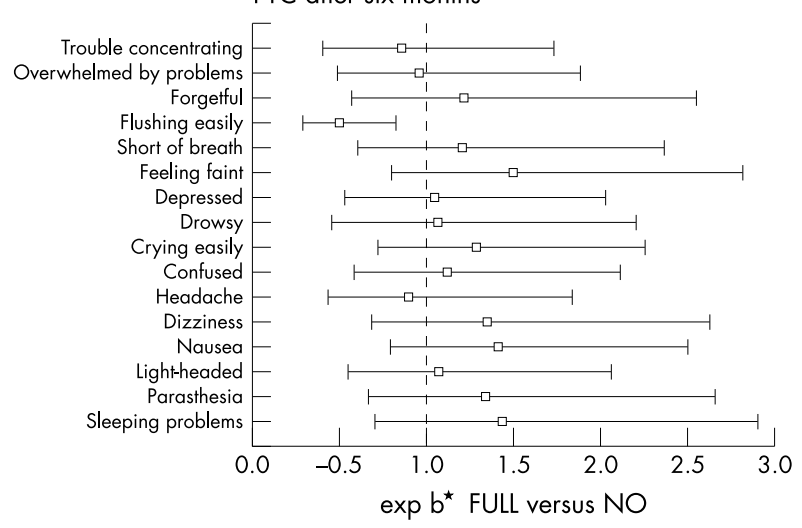

Figure 3 Post-traumatic complaints (PTC) after two weeks, three months, and six months in patients with MTBI with and without full bed rest. ${ }^{*} b$, coefficients from linear regression analysis of $\ln$ outcome variable (severity of post-traumatic complaints at three follow up occasions) on intervention (FULL versus $\mathrm{NO}$ ) after adjustment for sex, social situation, headache, and dizziness and vomiting in the emergency room.

The number of patients in our study was lower than expected, given the large number of patients with MTBI presenting to our hospital during the inclusion period. Since the rate of non-inclusion was caused mostly by work strain in the emergency department, it seems unlikely that the enrolled patients represented a selection of patients for whom bed rest was less or more effective. A larger study would have been more attractive but in our opinion the present results support the conclusion that bed rest does not improve outcome at six months after MTBI. The null hypothesis that bed rest after MTBI does not improve outcome at six months could not be rejected statistically. However, it is very unlikely that a larger
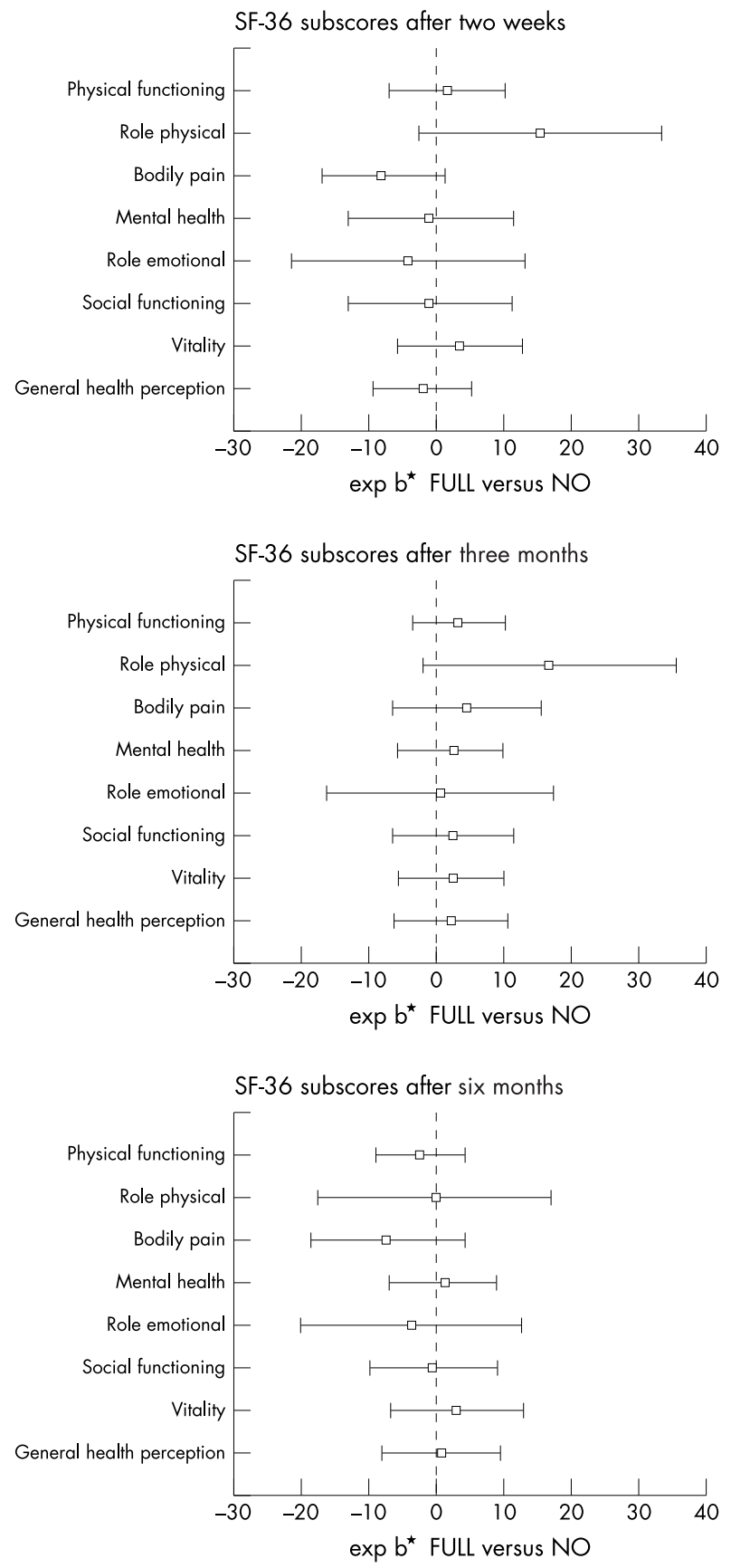

Figure 4 Medical outcomes study 36 item short form health survey (SF-36) subscores after two weeks, three months, and six months in patients with MTBI with and without six days' full bed rest. *b,

difference from linear regression analysis of outcome variable (SF-36 at three follow up occasions) in intervention groups (FULL versus NO) after adjustment for baseline differences in sex, social situation, headache, and dizziness and vomiting in the emergency room.

sample size would have shown a favourable effect of bed rest because at six months' follow up, for most outcome variables there was a trend that favoured the NO group.

The follow up rates of $87 \%$ (FULL) and $61 \%$ (NO) at six months were similar to those in earlier studies. ${ }^{16}{ }^{28}$ Our evaluation was done at the outpatient clinic and it proved impossible to achieve complete follow up in this group of relatively young, working, and often fully recovered patients. Although we do not know the reasons why fewer patients in the NO group showed up, we found that most patients who did not show up after six months had no complaints at three months. This finding supports the idea that the absence of 
PTC was a reason for not showing up for follow up in the whole group but that patients in the FULL group may have been more motivated to show up for follow up because of their more intensive treatment. If this is true, then the severity of PTC in both groups was overestimated and this bias would have been larger in the NO group than in the FULL group. As a consequence, the negative effect of bed rest at six months should have been even more pronounced.

\section{Implications for patients with MTBI}

Although we did not find a clear effect of bed rest on outcome after MTBI, some notable trends became apparent from this study. Firstly, during the first days following an MTBI, patients who were advised to take full bed rest reported significantly less dizziness than patients who were advised not to take bed rest. However, patients in the FULL group found it more difficult to comply with the advice to take bed rest and seemed to use more oral analgesics. Secondly, almost all PTC after two weeks tended to be less severe in the FULL group, while after six months there were hardly any differences. It was especially the physical complaints that seemed to be favourably influenced by bed rest in the short term, while this positive effect of bed rest completely disappeared or was even reversed later. Thirdly, bed rest also had a slight positive effect on physical health as measured by the SF-36 after two weeks, but this positive effect may have been offset by the increased experience of bodily pain and the slightly worse mental health shortly after the intervention period.

In view of these findings, bed rest probably can palliate dizziness during the first week after the trauma. We do not recommend bed rest to improve outcome after MTBI.

\section{Authors' affiliations}

J R de Kruijk, A Twijnstra, Department of Neurology, University Hospital Maastricht, The Netherlands

P Leffers, Department of Epidemiology, Maastricht University, The Netherlands

S Meerhoff, J Rutten, Faculty of Medicine, Maastricht University, The Netherlands

\section{REFERENCES}

1 Kraus J, McArthur D, Silverman T, et al. Epidemiology of brain injury. In: Narayan R, Wilberger J, Povlishock J, eds. Neurotrauma. New York: McGraw-Hill, 1996:13-30.

2 Thornhill S, Teasdale G, Murray G, et al. Disability in young people and adults one year after head injury: prospective cohort study. BM 2000;320: 1631-5

3 Meerhoff S, Kruijk de J, Rutten J, et al. De incidentie van traumatisch schedel: of hersenletsel in het adherentiegebied van het Academisch Ziekenhuis Maastricht in 1997. Ned Tijdschr Geneeskd 2000;144:915-23.

4 Haase J. Social-economic impact of head injury. Acta Neurochi 1992;55(suppl):75-9.

5 Collins MW, Grindel CH, Lovell MR, et al. Rehabilitation of persons with traumatic brain injury. JAMA 1999;282:974-83.
6 King S. Emotional, neuropsychological, and organic factors: their use in the prediction of persisting postconcussion symptoms after moderate and mild head injuries. J Neurol Neurosurg Psychiatry 1996;61:75-81.

7 Alexander $M$. Mild traumatic brain injury: pathophysiology, natura history, and clinical management. Neurology 1995;45:1253-60.

8 Levin H, Mattis S, Ruff R, et al. Neurobehavioral outcome following minor head injury: a three-center study. J Neurosurg 1987;66:234-43.

9 Rutherford W. Postconcussion symptoms: relationship to acute neurological indices, individual differences, and circumstances of injury. In: Levin HS, Eisenberg HM, Benton AL, eds. Mild head injury. New York: Oxford University Press, 1989:217-40.

10 Bohnen N, Wijnen G, Twijnstra A, et al. The constellation of late post-traumatic symptoms of mild head injury patients. J Neurol Rehabil 1995;9:33-9.

11 van der Naalt J, Zomeren A, Sluiter W, et al. One year outcome in mild and moderate head injury: the predictive value of acute injury characteristics related to complaints and return to work. J Neurol Neurosurg Psychiatry 1999;66:207-13.

12 Paniak C, Phillips K, Toller-Lobe G, et al. Sensitivity of three recent questionnaires to mild traumatic brain injury-related effects. J Head Trauma Rehabil 1999:14:211-9.

13 Minderhoud J, Boelens M, Huizinga J, et al. Treatment of minor head injuries. Clin Neurol Neurosurg 1980;82:127-40.

14 King N, Crawford S, Wenden F, et al. Interventions and service need following mild and moderate head injury: the Oxford Head Injury Service. Clin Rehabil 1997;11:13-27.

15 Paniak C, Toller Lobe G, Reynolds S, et al. A randomized trial of two treatments for mild traumatic brain injury: 1 year follow-up. Brain Inj 2000;14:219-26.

16 Wade D, King N, Wenden F, et al. Routine follow up after head injury: a second randomised trial. J Neurol Neurosurg Psychiatry 1998;65:177-83

17 Bohnen NI, Twijnstra A, Jolles J. A controlled trial with vasopressin analogue (DGAVP) on cognitive recovery immediately after head trauma. Neurology 1993;43:103-6.

18 Merchant RE, Bullock MR, Carmack CA, et al. A double-blind, placebo-controlled study of the safety, tolerability and pharmacokinetics of CP-101,606 in patients with a mild or moderate traumatic brain injury. Ann NY Acad Sci 1999:890:42-50.

19 Chapman EH, Weintraub RJ, Milburn MA, et al. Homeopathic treatmen of mild traumatic brain injury: a randomized, double-blind, placebo-controlled clinical trial. J Head Trauma Rehabil 1999:14:521-42.

20 van 't Hooft F. Commotio cerebri en andere gevolgen van schedeltraumata; ziekteverloop en prognose. Utrecht: Rijksuniversiteit Utrecht, 1973.

21 de Kruiik J, Leffers P, Twijnstra A. Management of mild traumatic brain injury: lack of consensus in Europe. Brain Inj 2001;15:117-24.

22 Allen C, Glasziou P, Del Mar C. Bed rest: a potential harmful treatment needing more careful evaluation. Lancet 1999;354:1229-33.

23 Aaronson N, Muller M, Cohen $\mathrm{P}$, et al. Translation, validation, and norming of the Dutch language version of the SF-36 health survey in community and chronic disease populations. J Clin Epidemiol 1998;51:1055-68

24 McHorney C, Ware J, Raczek A. The MOS 36-item short-form health survey (SF-36). II. Psychometric and clinical tests of validity in measuring physical and mental health constructs. Med Care 1993;31:247-63.

25 Levin $\mathbf{H}$. Treatment of postconcussional symptoms with CDP-choline. J Neurol Sci 1991;103(suppl):s39-42.

26 Nell V, Yates DW, Kruger J. An extended Glasgow coma scale (GCS-E) with enhanced sensitivity to mild brain injury. Arch Phys Med Rehabil 2000;81:614-7.

27 Ruff RM, Jurica P. In search of a unified definition for mild traumatic brain injury. Brain Inj 1999;13:943-52.

28 Paniak C, Toller-Lobe G, Durand A, et al. A randomized trial of two treatments for mild traumatic brain injury. Brain Inj 1998;12:1011-23. 